\title{
Relationship between the Chinese Language Classroom Environment and Students' Motivation to Learn Mandarin in Malaysia
}

\author{
P. K. Veloo ${ }^{1, *}$, Wang Yang ${ }^{1}$, Gurnam Kaur ${ }^{1}$, Parmjit Singh ${ }^{2}$ \\ ${ }^{1}$ Faculty of Education, SEGi University, Malaysia \\ ${ }^{2}$ Faculty of Education, MARA University of Technology, Malaysia
}

Received June 28, 2019; Revised September 5, 2019; Accepted September 12, 2019

Copyright $\subseteq 2019$ by authors, all rights reserved. Authors agree that this article remains permanently open access under the terms of the Creative Commons Attribution License 4.0 International License

\begin{abstract}
Associations between the nature of Mandarin Classroom Environments and Malaysian Chinese Independent High school students' motivation to learn Mandarin was investigated using a perceptual measure approach. A sample of 460 grade 8 students from 4 Independent Chinese High schools were involved in the study. The Mandarin Classroom Environment Inventory (CLCEI) (Chua, 2004) was used to investigate teachers' and students' perceptions towards their Mandarin classroom learning environments in six dimensions, namely 'Student Cohesiveness', 'Teacher Support', 'Involvement', 'Cooperation', 'Task Orientation' and 'Equity'. Students' motivation to learn Mandarin was examined using the Chinese Language Motivation Scale (CLMOTS) (Soh, 1993). Two statistical procedures, simple correlational analysis and multiple regression analysis, were used to examine the relationships between students' motivation to learn Mandarin and the nature of their Mandarin classroom learning environments. The results show that students' motivation to learn Mandarin was positively correlated with all the six learning environment dimensions. Multiple regression analysis show that students' motivation to learn Mandarin was associated with three dimensions of the learning environments, 'Teacher Support', 'Task Orientation', and Equity. Task Orientation had the most significant association with students' motivation to learn Mandarin.
\end{abstract}

Keywords Classroom Learning Environment, Motivation, Chinese Language, Task Orientation

\section{Introduction and Background}

Students have spent close to 15,000 hours in classrooms by the time they complete high school (Fraser, 2002; Velayutham, 2012). Therefore what happens within these classrooms, such as the nature of the teaching and learning and the interactions experienced by students, are likely to have a profound impact on students' outcomes. Traditionally school effects research has tended to rely heavily on the assessment of subject related academic achievement and other learning outcomes (Fraser, 2007). Academic factors alone do not provide a complete picture of the overall academic process that occurs in the classroom. Many things that happen in the classroom, and most importantly the atmosphere the teacher creates during the lesson impacts on how students learn. Classroom learning environment is an important educational area that has received much attention from educational researchers. Despite its importance, educators tend to rely heavily on achievement and other outcomes which do not provide a complete picture of the educational processes within the classroom (Fraser, 2002).

The field of leaning environment research focuses on classroom life, usually from the students' perspective (Fraser, 2007). Research conducted over the past 40 years has consistently shown that the quality of the classroom learning environment in schools is an important determinant of students' learning engagement (Fraser, 2007). That is, students are likely to learn better when they perceive their classroom learning environment positively. According to Hanrahan (2002), classroom dynamics can be influential in alienating students even before they have a chance to begin to engage with concepts taught in that classroom.

Malaysia is a multiracial country and has a unique system of education. Parents who send their children to public primary schools may choose from among three languages as the medium of instruction, namely Malay, Mandarin or Tamil. The medium of instruction at public 
secondary schools is Malay. At the secondary level, about 60 Mandarin-medium secondary schools exist but operate outside the Malaysian public-school system and are referred to as Independent Chinese High Schools. In these schools, Mandarin is the medium of instruction and is also taught as a single subject. Studies on the teaching and learning of Mandarin at the secondary level collectively reveal that Chinese students faced various difficulties in learning Mandarin in Malaysian Chinese schools. These difficulties ranged from a lack of trained teachers to teaching methodology adopted by the teachers and the curriculum used in schools (Fan, 1998; Chong, Y.F., 2004; Chong, S.C., 2004). No studies on classroom learning environment have been conducted on students' learning of Mandarin in Independent Chinese High Schools in Malaysia. The purpose of this study was to investigate the perceptions of a sample of Grade-8 students from several Independent Chinese High Schools, of their Mandarin classroom learning environments in six dimensions, namely 'Student Cohesiveness', 'Teacher Support', 'Involvement', 'Cooperation', 'Task Orientation' and 'Equity and their relationship to students' motivation to learn Mandarin. Specifically, the study sought answers to the following three research questions:

1. What are the perceptions of the sample of Grade- 8 students of their Mandarin classroom learning environment and their motivation to learn Mandarin?

2. What is the relationship between Grade- 8 students' perceptions of their Mandarin classroom learning environment and their motivation to learn Mandarin?

3. Which of the dependent variables were significant predictors of student motivation to learn Mandarin?

\section{Literature Review}

The notion that there exists a learning environment which mediates aspects of learning was mooted by Kurt Lewin who pioneered studies of student learning from a focus on the individual to a focus on processes between individuals (Crosbie-Brunett \& Lewis, 1993). Bandura (1986) acknowledged that the social cognitive theory's concept of reciprocal interactions, stemmed from Lewin's concepts on human behaviour. An integral element of classroom environment theory was Moos' (1979) conceptual framework for human environments, which was significantly influenced by the work carried out by Lewin. Moos extended Lewin's environmental influences by focusing on the psychosocial aspect of a range of environments including the classroom environment. Herbert Walberg and Rudolf Moos independently studied learners' perceptions of their learning environment across a spectrum of learning situations. Walberg's studies were linked to the Harvard Project Physics (Walberg, 1972) and developed the Learning Environment Inventory (LEI). Moos' research led to the development of the Classroom Environment Scale (CES) (Moos \& Trickett, 1987).
Classroom environment studies revealed that there were associations between students' perceptions of their classroom learning environments and their cognitive and affective learning outcomes (Fraser, 1994).

Theoretically the classroom learning environment can be viewed in terms of Banduraecs (1986) social cognitive theory, which sees human behaviour as a series of reciprocal interactions between personal influences, environmental features and behaviours. The concept of reciprocal interactions illustrates how the environment can affect thoughts and behaviour of students, in particular student motivation to learn, in a classroom. According to Urdan and Schoenfelder (2006) the social-cognitive view of student motivation can explain how altering controllable factors in the classroom environment could considerably enhance students' motivation to learn. Urdan and Schoenfelder (2006) proposed that enhancing student motivation requires attention to the key features of the classroom learning environment that are likely to influence student motivation. An issue that is of concern in classroom environment studies relates to gender characteristics. Sources of inequality in the classroom learning environment need to be understood and addressed to optimize learning (PISA, 2009).

Reviews on early classroom environment studies revealed that there were associations between students' perceptions of their classroom learning environments and their cognitive and affective learning outcomes (Fraser, 1994). Associations between learning outcomes and students' perceptions of classroom learning environments were found in Chemistry classes (Fraser \& McRobbie, 1995), in Biology classes (Fisher, Henderson, \& Fraser, 1997) and in Mathematics classes (Fisher, Fraser, \& Rickards, 1997) for Australian students. Chua, Wong and Chen (2009) found that students' perception of their Chinese Language classroom learning environment was related to their motivation to learn the language. The literature reviewed provided solid support for the investigation of grade-8 students' perceptions of their Mandarin classroom learning environment and its relationship to students' motivation to learn Mandarin.

\section{Research Methodology}

\subsection{Sample}

The sample of respondents in this study were 460 Grade 8 students from 4 Independent Chinese High School in the Klang Valley, Malaysia.

\subsection{Instruments}

Two instruments, the Chinese Language Classroom Environment Inventory (CLCEI) (Chua, Wong, \& Chen, 2006), and the Chinese Language Motivation Scale (CLMOTS) (Soh, 1993), were adopted in this study to 
measure students' perceptions of their Chinese Language classroom learning environments and motivation to learn the Chinese Language respectively. The CLCEI is a 48-item, validated bilingual instrument in which every item is written in both English and Chinese (Chua, Wong \& Chen, 2006). The items were presented in two languages to assist students who had difficulty in fully understanding the meaning of the Chinese items. The 48 items of the CLCEI examines 6 dimensions of the Mandarin classroom learning environments, namely, Student Cohesiveness, Teacher Support, Involvement, Cooperation, Task Orientation and Equity. Student Cohesiveness refers to the extent to which students know, help and are supportive of one another; Teacher Support refers to the extent to which the teacher helps, befriends, trusts and is interested in students; Involvement refers to the extent to which students have attentive interest, participate in discussions, do additional work and enjoy the class; Cooperation refers to the extent to which students cooperate rather than compete with one another on learning tasks; Task Orientation refers to the extent to which the teacher completes activities that have been planned or completes tasks that need to be performed in order to meet certain goals, or certain performance standard; Equity is the extent to which students are treated equally by the teacher. Each of the 6 dimensions is evaluated by 8-items of the CLCEI. Content validity and internal consistency was established both in the pilot study as well as in the actual study. Cronbach alpha for the overall instrument was 0.96 . For the subscales it ranged from 0.84 on Student Cooperation scale to 0.95 on Teacher Support. Factor Analysis of student responses showed that 46 of the 48 items loaded on six distinct factors.

Students' motivation to study Mandarin was measured by CLMOTS, an 11-item motivation instrument developed by Soh (1993). The 11 items of the CLMOTS are related to students' involvement in classroom learning tasks. The items of the CLMOTS have a five-point response scale. The 4 response alternatives, $1=$ 'Always Not True', $2=$ 'Not True', $3=$ 'Not Sure' $4=$ 'True' and $5=$ 'Always True', indicate the degree of applicability of the statements to the students. The internal consistency of CLMOTS was found to be 0.87 .

\subsection{Data Analysis}

Relationships between the students' perceptions of their
Chinese Language classroom environment as assessed by CLCEI and their motivational outcome as measured by the CLMOTS were investigated using two main methods of analysis, namely:

1. Simple correlational analysis of associations between students' motivation to learn the Chinese Language and each individual environment scale,

2. Multiple regression analyses of associations between students' motivation to learn the Chinese Language and the set of six environment scales.

Students' perceptions of their Mandarin classroom learning environment were determined by computing the means and standard deviation of the overall perception scores and the perception scores on each of the 6 subscales. To explore gender differences in students' perceptions of their learning environment, independent sample $t$-tests were performed.

Pearson Product Moment correlation $r$ was computed first to examine the associations between the nature of the Chinese Language classroom learning environment and students' motivation to learn Mandarin. In order to reduce possible Type I error that could be caused by treating the six scales of the CLCEI as six independent scales in the correlational analysis, the multiple regression statistical procedure was also carried out for this investigation. In the latter analysis, the motivation score was used as the dependent variable and the set of six environment scales were used as the independent variable.

The statistics used for reporting the results of the multiple regression analyses were the standardised regression coefficient $(\beta)$ indicating the associations between the dependent variable and each independent variable in the regression equation, the overall multiple correlation coefficient (R) and the R-squared which indicates the amount of variance in students' motivation that was accounted for by the environment scales. The result indicated the associations between student's perceived classroom learning environment and their motivation to learn Mandarin.

\section{Results}

Table 1 shows the means and standard deviation of the overall perception scores and the perception scores on each of the 6 subscales, the $t$ - and $p$-values. 
Table 1. Distribution of the Means, Standard Deviation, $\mathrm{t}$ - and p-values of the Perception of Grade 8 Students of their Mandarin Classroom Learning Environment

\begin{tabular}{|c|c|c|c|c|}
\hline \multirow{2}{*}{ Environment Scales } & \multicolumn{2}{|c|}{ Means (SD) } & \multirow{2}{*}{ t-values } & \multirow{2}{*}{$p$-values } \\
\cline { 2 - 4 } & Males $(\mathrm{n}=239)$ & $\frac{\text { Females }}{(\mathrm{n}=221)}$ & & 0.12 \\
\hline Overall Persp. & $3.20(0.79)$ & $3.31(0.75)$ & -1.55 & $0.000^{* * *}$ \\
\hline Stu. Cohes. & $3.72(0.82)$ & $3.97(0.66)$ & -3.64 & 0.66 \\
\hline Tch. Supprt. & $3.04(1.11)$ & $2.68(0.89)$ & 1.66 & 0.10 \\
\hline Involvement & $2.82(0.89)$ & $3.57(0.84)$ & -2.81 & $0.005^{* *}$ \\
\hline Task. Orien. & $3.34(0.91)$ & $3.40(0.89)$ & -2.18 & $0.03^{*}$ \\
\hline Cooperation & $3.21(0.98)$ & $3.15(1.04)$ & -0.61 & 0.55 \\
\hline Equity & $3.09(1.05)$ & & \\
\hline
\end{tabular}

*Significant at $p<0.05 ; * *$ significant at $p<0.01$; ***significant at $p<0.001$

The perceptions of female students were statistically significantly higher than that of male students on three subscales. On student cohesiveness subscale, differences in the scores for male and female students was statistically significant $(M=3.72, S D=0.66)$ and for female $(M=3.97$, $S D=0.66 ; t(458)=-3.64, p<0.001$, two-tailed $)$. On task orientation subscale, differences in the scores for male and female students was statistically significant $(M=3.34, S D$ $=0.91)$ and for female $(M=3.57, S D=0.84 ; t(458)=-$ $2.81, p<0.01$, two-tailed). On students' cooperation, differences in the scores for male and female students was statistically significant $(M=3.21, S D=0.98)$ and for female $(M=3.40, S D=0.89 ; t(458)=-2.18, p<0.05$, two-tailed). The finding of gender differences in 'student cohesiveness' in Mandarin classes in this study was consistent with the findings of a previous study in Singapore by Chua, Wong and Chen (2006). Other environment studies conducted using the WlHlC questionnaire have indicated that there were gender differences in the 'Cooperation', 'Task Orientation' and 'Equity' scales (Thorpe \& College, 2000, Margianti \& Fraser, 2000).

Table 2. Distribution of the Means, Standard Deviation, of the Motivation of Grade 8 Students to Learn Mandarin

\begin{tabular}{|c|c|c|c|c|c|}
\hline \multirow{2}{*}{$\begin{array}{c}\text { Environment } \\
\text { Scales }\end{array}$} & \multirow{2}{*}{$\begin{array}{c}\text { No } \\
\text { of } \\
\text { items }\end{array}$} & \multicolumn{2}{|c|}{ Means (SD) } & \multirow[b]{2}{*}{$t$-value } & \multirow[b]{2}{*}{$p$-value } \\
\hline & & $\begin{array}{c}\text { Males } \\
(n=239)\end{array}$ & $\begin{array}{l}\text { Females } \\
(n=221)\end{array}$ & & \\
\hline $\begin{array}{c}\text { Overall } \\
\text { Motivation }\end{array}$ & 11 & \multicolumn{2}{|c|}{$3.37(0.83)$} & & \\
\hline $\begin{array}{l}\text { Motivation } \\
\text { by Gender }\end{array}$ & 11 & $\begin{array}{c}3.20 \\
(0.89)\end{array}$ & $\begin{array}{c}3.56 \\
(0.75) \\
\end{array}$ & 4.83 & $0.000 * * *$ \\
\hline
\end{tabular}

$* * *$ significant at $p<0.001$

The results in Table 2 show that the mean scores of the female students on the motivation scale was statistically significantly higher than that of their male counterparts. Female student were more motivated to study Mandarin than male students from the classes investigated in the study.

Results in Table 3 show that the correlation between each of the six environment scales and the students' motivation score were all positive. Pearson Correlation Coefficients $(r)$ for all the six scales of the CLCEI ranged from 0.32 (for the 'Student Cohesiveness') to 0.72 (for the
'Task Orientation'), and they were all significant at $\mathrm{p}<.01$. The results showed that the 'Task Orientation' scale had the greatest value of $r$. It indicated that the relationship between students' motivation to learn the Chinese Language and the 'Task Orientation' dimension of the Chinese Language classroom learning environments was the strongest among all the six scales of the CLCEI.

For the multiple regression analysis, the multiple correlation (R) was 0.74 , meaning that the set of six scales accounted for $55 \%$ of the variance in students' motivation.

In order to determine which individual CLCEI scales contributed the most to explaining the variance in the motivation scores, an inspection was made of the values of standardised regression coefficients (i.e., the associations between the dependent variable and each independent variable in the regression equation). Table 3 shows that the number of significant regression weights for the multiple regression analysis was on 3 scales ('Teacher Support', 'Task Orientation' and Equity scales). These regression weights indicate whether a specific CLCEI scale makes a unique contribution to the variance in students' motivation scores when scores on the other five classroom environment scales are mutually controlled. On examination of the signs and magnitudes of the significant $\beta$ weights in Table 3 , it showed that all the significant $\beta$ weights were positive. Furthermore, the $\beta$ weight for the 'Task Orientation' scale was $0.55(p<.001)$. As for the 'Teacher Support' scale the $\beta$ weights was $0.13(p<.01)$ and for the Equity scale the $\beta$ weights was $0.12(p<0.05)$.

Table 3. Pearson's Correlation (r), Standardised Regression Coefficient $(\beta)$, and Multiple Correlation (R), for Associations between Scores on the CLCEI Scales and Students' Motivation Scores

\begin{tabular}{|c|c|c|c|c|}
\hline Scales & $r$ & $p$-values & $\beta$ & $p$-values \\
\hline Stu Coh. & 0.32 & 0.000 & -0.038 & 0.364 \\
\hline Tch.Supprt & 0.55 & 0.000 & 0.131 & $0.005^{* *}$ \\
\hline Involvement & 0.48 & 0.000 & -0.004 & 0.935 \\
\hline Task. Ori. & 0.72 & 0.000 & 0.552 & $0.000^{* * *}$ \\
\hline Cooperation. & 0.51 & 0.000 & 0.065 & 0.191 \\
\hline Equity & 0.61 & 0.000 & 0.121 & $0.011^{*}$ \\
\hline \multicolumn{2}{|c|}{ Multiple Correlation. $\mathrm{R}=0.74$} & $\mathrm{R}^{2}=0.550$ \\
\hline
\end{tabular}

Significant ${ }^{*} p<0.05 ; * * p<0.01 ; * * * p<0.001$ 
In summary, both the simple correlation and multiple regression analyses showed that there was a strong relationship between the 'Task Orientation' dimension of the classroom learning environment and the students' motivation to learn the Chinese Language. The result implied that in a task-oriented class (i.e., a classroom environment with a high task focus), students would be motivated to learn the Chinese Language. The finding is consistent with findings of other previous studies on motivation. Chua, Wong \& Chen (2009) found that Task Orientation is strongly associated with students' motivation to learn the Chinese Language. Ruiz-Gonzalez, Videra \& Moreno-Murcia (2015) found that promotion of an educational task-oriented environment where learners perceive their progress and make them feel more competent, will allow them to be intrinsically motivated by tasks, and therefore they will have more fun. Nicholls (1984) found that when students are intrinsically motivated, they are generally task-oriented. Stipek (1993) also found that academically motivated students are usually those students who are task-oriented. Highly motivated students would seek out strategies or develop understanding of knowledge and skills that are needed to complete their assigned tasks. The Chinese conceptions of education have been much influenced by Confucian thinking (Biggs, 1996; Scollon, 1999). Chinese teachers and students regard education as a serious undertaking that is least likely to be associated with light-heartedness but requires deep commitment and painstaking effort and as such can be associated with task orientation (Hu, 2002).

In this study it was also found that Teacher Support and Equity were also related to student motivation to learn the Mandarin. Classes in which students see their teachers as being supportive and being equally fair to all students motivated students to learn. Davis (2006) and Koca (2016) found that middle school students and teachers who perceived their relations as supportive and positive reported enhanced motivation.

This study showed that there were statistically significant associations between the nature of the Mandarin classroom learning environment and students' motivation to learn the language. The most important finding of this study was that, 'Task Orientation' dimension of the classroom learning environment was a strong predictor of Grade-8 students' motivation to learn Mandarin in the Independent Chinese High Schools investigated. This means that in the Mandarin classroom the teacher should complete activities that have been planned in order to meet certain goals, or learning outcomes. Motivation to learn is also influenced by the kind of teacher-student relationship that exists in the classroom learning environment (Davis, 2006; Кoca, 2016). A teacher who treats all students equally and is friendly towards them would motivate students to learn the subject he or she is teaching.

Based on the finding that students' motivation was strongly associated with the 'Task Orientation' dimension of the classroom learning environment, future studies should explore whether there is a cause-and-effect relationship between task-oriented classrooms and students' motivation to learn. In order to investigate this cause-effect relationship, further research involving the deliberate manipulation of the nature of the classroom environment, in particular the Task Orientation dimension, is recommended. It would also be interesting to investigate if there are cultural factors at play in the Mandarin classroom learning environment. An underlying cultural factor that influences Chinese education in Malaysia and elsewhere is the Confucian ideology which emphasizes hard work and respect for teachers. The influence of this factor on learning in Chinese classrooms has to be explored further.

\section{Conclusions}

This study showed that there were statistically significant associations between the nature of the Mandarin classroom learning environment and students' motivation to learn Mandarin. The most important finding of this study was that, 'Task Orientation' dimension of the classroom learning environment was a strong predictor of the students' motivation to learn Mandarin. This finding is similar to the findings from previous motivational studies (Chua, Wong \& Chen, 2009; Nicholls, 1984; Stipek, 1993), in which students could be motivated to learn if task-oriented activities are used in the classrooms. Motivation to learn is also influenced by the kind of teacher-student relationship that exists in the classroom learning environment (Davis, 2006; Koca, 2016).

\section{Acknowledgement}

The study reported in this paper is part of a larger project undertaken by the second author as part of her Master of Education Thesis at the SEGi University Malaysia. We wish to acknowledge with thanks for the help and support given by the Institute of Graduate Studies of SEGi University and the principals and students of the 4 secondary schools that participated in the study.

\section{REFERENCES}

[1] Bandura, A. (1986). Social foundations of thought and action: A social cognitive theory. Englewood Cliffs, NJ: Prentice Hall.

[2] Biggs, J.B. (1996).Western misperceptions of the Confucian-heritage learning culture. In D.A. Watkins and J.B. Biggs (eds) The Chinese Learner: Cultural, Psychological and Contextual Influences (pp. 45-67). Hong Kong: CERC and ACER.

[3] Chong, S. C. (2004). Sikap pelajar Tingkatan Empat 
terhadap pembelajaran Bahasa Cina di sekolah menengah kebangsaan kawasan Kuala Lumpur. Kertas Projek Sarjana Pendidikan. Universiti Malaya, Kuala Lumpur

[4] Chong, Y. F. (2004). Satu tinjauan tentang masalah pembelajaran prosa klasik Bahasa Cina di kalangan pelajar Tingkatan Satu. Kertas Projek Sarjana Pendidikan. Universiti Malaya, Kuala Lumpur

[5] Chua, S. L. (2004). An Investigation of the Nature of Chinese Language Classroom Learning Environments in Singapore Secondary Schools. A thesis submitted to the National Institute of Education, Nanyang Technological University, Singapore, in fulfilment of the requirement for the degree of Doctor of Philosophy, Singapore.

[6] Chua, S. L., Wong, F. L., \& Chen, D. (2006). Validation of the 'Chinese language classroom learning environment inventory' for investigating the nature of Chinese language classrooms. Issues in Educational Research, 16 (2), 139-151.

[7] Chua, S. L., Wong, F. L., \& Chen, D. (2009). Associations between Chinese Language classroom environments and students' motivation to learn the language. Australian Journal of Educational \& Developmental Psychology, 9, 53-64.

[8] Crosbie-Brunett, M., \& Lewis, E. A. (1993). Theoretical contributions from social and cognitive behavioural psychology. In P. G. Boss, W. J. Doherty, R. LaRossa, W. R. Schumm \& S. K. Streinmetz (Eds.), Sourcebook of family theories and methods: A contextual approach (pp. 531-557). New York: Plenum Press.

[9] Davis, H. A. (2006). Exploring the contexts of relationship quality between middle school students and teachers. The Elementary School Journal: Special Issue on the Interpersonal Contexts of Motivation and Learning, 106, 193-223.

[10] Fan P. S. (1998). Masalah salah tulis dan sala guna perkataan dalam karangan Bahasa Cina pelajar Tingkatan Satu. Kertas Projek Sarjana Pendidikan. Universiti Malaya, Kuala Lumpur

[11] Fisher, D. L., Fraser, B.J., \& Rickards, T. (1997). Gender and cultural differences in teacher student interpersonal behaviour. Paper presented at the annual meeting of the American Educational Research Association, Chicago, IL.

[12] Fisher, D. L., Henderson, D., \& Fraser, B.J. (1997). Laboratory environments and student outcomes in senior high school biology. American Biology Teacher 59, 214-219.

[13] Fraser, B. J. (1994). Research on classroom and school climate. In D. Gabel (Ed.). Handbook of research on science teaching and learning (pp. 493-541). New York: Macmillan.

[14] Fraser, B. J. (2002). Learning environments research: Yesterday, today and tomorrow. In S. C. Goh, \& M. S. Khine (Eds.). Studies in educational learning environment: An international perspective (pp. 1-25). Singapore: World Scientific.

[15] Fraser, B. J. (2007). Classroom learning environments. In S. K. Abell \& N. G. Lederman (Eds.), Handbook of research on science education (pp. 103-124). Mahwah, NJ:
Lawrence Erlbaum Associates.

[16] Fraser, B. J., \& McRobbie, C. J. (1995). Science laboratory classroom environments at schools and universities: A cross-national study. Educational Research and Evaluation, 1, 289-317.

[17] Hanrahan, M. (2002, July). Learning science: Revisiting humanist dimensions of intellectual engagement. Paper presented at the annual meeting of the Australasian Science Education Research Association, Townsville, Australia.

[18] Hu, G. (2002). Potential Cultural Resistance to Pedagogical Imports: The Case of Communicative Language Teaching in China, Language Culture and Curriculum, 15:2, 93-105, DOI: $10.1080 / 07908310208666636$

[19] Koca, F. (2016). Motivation to Learn and Teacher-Student Relationship. Journal of International Education and Leadership, 6(2), 1-20.

[20] Moos, R. H. (1979). Evaluating educational environments: Procedures, measures, findings and policy implications. San Francisco: Jossey-Bass.

[21] Moos, R. H., \& Trickett, E. (1987). Classroom Environment Scale manual (2nd Ed.). Palo Alto: Consulting Psychology Press.

[22] Nicholls, J. G. (1984). Achievement motivation: Conceptions of ability, subjective experience, task choice, and performance. Psychological Review, 91(3), 328-346.

[23] Programme for International Student Assessment (2009). Equally prepared for life?: How 15 year-old boys and girls perform in school. Paris: OECD Publishing.

[24] Ruiz-González, L., Videra, A., Moreno-Mureia, J. A. (2015). Predictive power of task orientation, general self-efficacy and self-determined motivation on fun and boredom. Motriz: rev. educ. fis. 21(4). http://dx.doi.org/10. 1590/S1980-65742015000400004

[25] Scollon, S. (1999). Not to waste words or students: Confucian and Socratic discourse in the tertiary classroom. In E. Hinkel (ed.) Culture in Second Language Teaching and Learning (pp. 13-27). Cambridge: Cambridge University Press.

[26] Stipek, D.J. (1993). Motivation to learn: From theory to practice (2nd Ed). US: Allyn and Bacon.

[27] Soh, K. C. (1993). Measuring motivation to learn Chinese and English through self-reported feelings and behaviours. Singapore Journal of Education, 13(1), 44-50.

[28] Urdan, T., \& Schoenfelder, E. (2006). Classroom effects on student motivation: Goal structures, social relationships, and competence beliefs. Journal of School Psychology, 44, 331-349.

[29] Velayutham, S. (2012). The Influence of Classroom Environment on Students' Motivation and Self-Regulation. Thesis presented for the Degree of Doctor of Philosophy at Curtin University, Perth, Australia.

[30] Walberg, H. J. (1972). Social environment and individual learning: a test of the Bloom model. Journal of Educational Psychology, 63, 69-73. 